\title{
Gonadotropin-Releasing Hormone Agonists Are Effective in Long-term Treatment of Women with Abnormal Uterine Bleeding and Anticoagulant Therapy: Report of 3 Cases and Review of the Literature
}

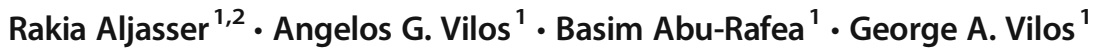 \\ Published online: 10 July 2020 \\ (C) The Author(s) 2020
}

\begin{abstract}
Purpose of Review To evaluate the efficacy of gonadotropin-releasing hormone agonist (GnRHa) in women with abnormal uterine bleeding (AUB) on anticoagulant therapy.

Recent Findings Prospective observational case series (Canadian Task Force Classification II-3) at University-affiliated teaching hospital. From January 2002 through December 2019, three premenopausal women on warfarin therapy were identified from our clinical practice. After clinical assessment, including Papanicolaou smear, endometrial biopsy, and pelvic sonography, a GnRHa was used to treat their AUB. Two women were receiving warfarin therapy (5-7 mg/day) for previous venous thromboembolism and one for mechanical heart valve replacement associated with Marfan's syndrome. All patients had additional comorbid conditions and were at high risk for traditional medical or surgical therapies. After treatment with GnRHa, all women reported menstrual reduction at 3 months and remained amenorrheic for 2 to 11 years, two of whom reached menopause.

Summary In properly assessed and selected premenopausal women with AUB receiving anticoagulant therapy and at high risk for traditional therapies, long-term GnRHa was an effective treatment in 3 patients.
\end{abstract}

Keywords Abnormal uterine bleeding · Anticoagulation · Gonadotropin-releasing hormone agonist · Heavy menstrual bleeding · Menorrhagia · Warfarin

This article is part of Topical Collection on Uterine Fibroids and Endometrial Lesions

Rakia Aljasser

dr.rakia@hotmail.com

Angelos G. Vilos

agvilos19@gmail.com

Basim Abu-Rafea

baburafea@gmail.com

George A. Vilos

george.vilos@lhsc.on.ca

1 The Fertility Clinic, Room E3-620A, London Health Sciences Center, Department of Obstetrics and Gynecology, Division of Reproductive Endocrinology and Infertility, Western University, 800 Commissioners Road East, London, ON N6A 4G5, Canada

2 Department of Obstetrics and Gynecology, King Khalid University Hospital, King Saud University, Riyadh, Saudi Arabia

\section{Introduction}

Abnormal uterine bleeding (AUB) is used to describe any departure from normal menstruation or from a normal menstruation pattern. The key characteristics of AUB are regularity, frequency, amount, and duration of flow, but each of these may exhibit considerable variability [1]. In general, AUB is experienced by approximately 20 to $30 \%$ of premenopausal women [2] and is a common debilitating condition that results in reduced hemoglobin, adversely affects quality of life, and is associated with significant use of health care resources [3].

Gynecologists managing women presenting with AUB deal with medical and/or anatomical conditions that, in conjunction with factors as age, hormonal, metabolic, and body mass index (BMI) changes, may contribute to AUB. Among these conditions are bleeding disorders, cardiovascular conditions requiring prosthesis, thromboembolic events requiring acute thrombolysis and/or long-term thromboprophylaxis, and cerebrovascular accidents. Traditional therapies for AUB, under these 
circumstances, may be ineffective, refused, contraindicated, difficult, or risky to perform.

Herein, we report our experience with 3 women with AUB, and various comorbidities and conditions requiring long-term anticoagulation therapy treated with long-term gonadotropinreleasing hormone $(\mathrm{GnRH})$ agonist with or without add-back therapy.

The patient demographics, presentation, treatment, and clinical outcomes are summarized in Table 1 .

\section{Case 1}

A 40-year-old woman, G3P2, BMI $24 \mathrm{~kg} / \mathrm{m}^{2}$, presented with AUB. She had been diagnosed with systemic lupus erythematosus (SLE) and carrier of lupus anticoagulant with history of two episodes of deep venous thrombosis (DVT). Consequently, she was on thromboprophylactic treatment using warfarin (Coumadin, Bristol-Myers Squibb, Montreal, QC) $5 \mathrm{mg}$ /day and hydroxychloroquine $200 \mathrm{mg}$ daily by mouth (Plaquenil, Sanofi Canada, Laval, QC). It was thought that the anticoagulation therapy may have been a contributor to her heavy vaginal bleeding and after discussing treatment options, she underwent endometrial ablation using a hot liquid thermal balloon (Thermablate, Idoman Canada, Toronto, Ontario).
Two years after endometrial ablation, she developed progressively increasing abnormal uterine bleeding resulting in iron deficiency anemia and requested additional therapy. After appropriate counseling and consultation with a hematologist, she was started on GnRH agonist therapy (Leuprolide acetate, Lupron, Abbvie Canada, Saint-Laurent, QC), 11.25 mg intramuscular injections every 3 months along with add-back therapy using $1 \mathrm{mg}$ of 17B-estradiol (Estrace, Acerus Pharmaceuticals, Mississauga, ON), and $100 \mathrm{mg}$ of micronized progesterone (Prometrium, Merck Canada, Kirkland, QC) per day. At 11 years of follow-up, she has remained amenorrheic and became menopausal at 51 years. The plan is to discontinue the GnRHa and add-back therapy but keep her anticoagulated indefinitely and reassess annually.

\section{Case 2}

A 54-year-old lady, G6P6, BMI $42 \mathrm{~kg} / \mathrm{m}^{2}$, was referred to our clinic with dysmenorrhea and iron deficiency anemia with hemoglobin of $80 \mathrm{~g} / \mathrm{L}$. She always had heavy menstrual bleeding but it became much worse in the last 3 years following anticoagulant therapy. She had 2 episodes of DVT and unprovoked pulmonary embolism (PE) 3 years prior and she was on $5 \mathrm{mg}$ of warfarin daily. A 52-mg levonorgestrel intrauterine system (LNG-IUS, Mirena, Bayer, Mississauga, ON) had been tried for 6 months but it was removed for making her

Table 1 Summary of patients' demographics, presentation, treatment and clinical outcomes

\begin{tabular}{|c|c|c|c|c|c|}
\hline & $\begin{array}{l}\text { Age } \\
\text { (years) }\end{array}$ & $\begin{array}{l}\text { BMI } \\
\left(\mathrm{kg} / \mathrm{m}^{2}\right)\end{array}$ & Presentation & Treatment & Outcome \\
\hline Case 1 & 40 & 24 & $\begin{array}{l}\text { - AUB } \\
\text { - SLE } \\
\text { - Carrier of lupus anticoagulant } \\
\text { - Two episodes of DVT }\end{array}$ & $\begin{array}{l}\text { - Failed endometrial } \\
\text { ablation } \\
\text { - Leuprolide acetate } \\
11.25 \mathrm{mg} \text { every } \\
3 \text { months plus } 1 \mathrm{mg} \\
\text { Estrace and } 100 \mathrm{mg} \\
\text { Prometrium daily }\end{array}$ & 11 years: amenorrhea, menopause \\
\hline Case 2 & 54 & 42 & $\begin{array}{l}\text { - AUB } \\
\text { - Two episodes of DVT } \\
\text { - Unprovoked PE } \\
\text { - Morbid obesity } \\
\text { - Hypertension } \\
\text { - Type-2 diabetes } \\
\text { - Gastroesophageal reflux } \\
\text { - Sleep apnea }\end{array}$ & $\begin{array}{l}\text { - Failed LNG-IUS } \\
\text { - Failed DMPA } \\
\text { - Goserelin } 10.8 \text { mg every } \\
\quad 3 \text { months }\end{array}$ & 2 years: amenorrhea, menopause \\
\hline Case 3 & 39 & 34.5 & $\begin{array}{l}\text { - AUB } \\
\text { - Marfan's syndrome } \\
\text { - Prosthetic aortic valve } \\
\text { - Multiple surgical procedures } \\
\text { for aortic dissection and thoracoabdominal } \\
\text { aneurysm } \\
\text { - Amaurosis fugax } \\
\text { - Hypertension } \\
\text { - } 5 \text { transient ischemic attacks } \\
\text { - Psoriatic arthritis }\end{array}$ & $\begin{array}{l}\text { - Goserelin } 10.8 \mathrm{mg} \text { every } \\
3 \text { months plus add-back } \\
\text { therapy norethindrone } \\
\text { acetate } 5 \mathrm{mg} / \text { day }\end{array}$ & 2 years: amenorrhea \\
\hline
\end{tabular}


bleeding unpredictable. In the last 8 months, she had also been treated with a course of depomedroxyprogesterone acetate (DMPA, Pfizer, Mississauga, ON) $150 \mathrm{mg}$ every 3 months but it was causing breakthrough bleeding and lower abdominal pain.

She had multiple medical conditions including morbid obesity, hypertension, diabetes type-2, gastroesophageal reflux, sleep apnea, and bursitis for which she was taking multiple medications.

After assessment of her pelvic organs including an endometrial biopsy indicating pseudodecidualized endometrium, she agreed to be treated with GnRH agonist and she was given goserelin (AstraZeneca, Mississauga, ON) $10.8 \mathrm{mg}$ subcutaneously every 3 months with iron supplements. After 3 months, she became amenorrheic and her hemoglobin increased to $132 \mathrm{~g} \backslash \mathrm{L}$. At 2 years, she was doing well on goserelin injections with no reported vaginal bleeding and the treatment was stopped due to achieving natural menopause at 56 years.

\section{Case 3}

A 39-year-old, G0P0, BMI of $34.5 \mathrm{~kg} / \mathrm{m}^{2}$ woman, presented with shortness of breath, chronic fatigue, and heavy menstrual bleeding (HMB) associated with iron deficiency anemia with hemoglobin of $79 \mathrm{~g} / \mathrm{L}$. Her uterine bleeding was cyclic in nature every 30 days, lasting up to 7 days and described as heavy associated with clots and moderate/severe dysmenorrhea.

She had been previously diagnosed with polycystic ovarian syndrome (PCOS) and she provided a positive family history of Marfan's syndrome. The patient herself also had been diagnosed with atypical Marfan's syndrome and she had multiple surgical procedures including a Bentall procedure for a dissection of the aortic arch with mechanical aortic valve replacement. She also had an elephant trunk procedure. After 10 months of the second procedure, her chronic thoracoabdominal dissection which extended down to the common iliac arteries and their bifurcation bilaterally became quite complex with multiple lumens and she began developing pseudocoarctation symptoms. Therefore, she underwent thoracoabdominal aneurysm repair with cardiopulmonary bypass. Later, she developed amaurosis fugax from thrombi on her prosthetic aortic valve with decrease in max and mean gradient observed by echocardiography.

In addition, the patient was known to have hypertension, psoriatic arthritis, degenerative disc disease, and provided a history of at least 5 transient ischemic attacks (TIA) for which, together with her mechanical aortic valve replacement, she required lifetime anticoagulation. Consequently, she was on warfarin, 5 to $7 \mathrm{mg}$ together with $81 \mathrm{mg}$ of aspirin daily in conjunction with antihypertensive medications.
Following appropriate history, physical examination, and assessment of her AUB, the management of this patient became quite a challenge due to limited options for both traditional diagnostic tests and therapeutic modalities.

Treatment options for this patient were even more challenging since traditional hormone therapies may be contraindicated in fully anticoagulated patients. Although there is some experience with anticoagulated patients treated with endometrial ablation using intrauterine balloons [ $\left.4^{\circ}\right]$ and/or resectoscopic surgery $\left[5^{\circ}\right]$, we felt that endometrial ablation was not an appropriate option for this patient being a high surgical risk and also being less than 40 years of age which is known factor for increased ablation failure.

We have previously published good clinical outcomes with the use of LNG-IUS in women with AUB and anticoagulant therapy $\left[6^{\circ}\right]$. However, this patient refused our proposed treatment with LNG-IUS. As a result, we proposed long-term treatment with a GnRH agonist with add-back therapy and she was treated with goserelin $10.8 \mathrm{mg}$ injections subcutaneously every 3 months and norethindrone acetate (NETA) $5 \mathrm{mg}$ daily.

At 2 years of follow-up, the patient was amenorrheic, maintained normal hemoglobin levels (provide the value) and satisfied with her treatment.

\section{Discussion}

Oral anticoagulation therapy has been reported to increase menstrual blood loss $\left[7^{\circ}, 8^{\circ}\right]$, with $70 \%$ of women on anticoagulant therapy experiencing changes in their menstrual cycle. Fifty percent experience a greater number of menstrual days, and $66 \%$ heavier menstrual bleeding, with a significant number of women experiencing flooding and passing clots [ $\left.9^{\circ}\right]$.

Treatment of women with AUB and anticoagulant therapy can be challenging since both surgical and medical therapies may be refused, contraindicated, or difficult to perform due to various comorbid conditions.

\section{Surgical Interventions}

\section{Endometrial Ablation}

Thermal Balloon Endometrial Ablation We have previously reported on 11 high-risk surgical candidates with AUB and anticoagulant therapy (coumadin) treated with thermal balloon (ThermaChoice, Gynecare, J\&J, New Jersey) endometrial ablation without stopping their anticoagulant therapy. At a median follow-up of 11 months, $7(64 \%)$ reported improvement in menstrual blood loss, $3(27 \%)$ of whom had amenorrhea [ $\left.4^{\circ}\right]$. 
Endometrial Resectoscopic Ablation Goldenberg et al. reported on 11 patients with hematologic disorders, who had menometrorrhagia and failed medical therapy, treated with resectoscopic endometrial ablation. After 1-year follow-up, the patient's satisfaction was high $(10 / 11)$ with an average increase in hemoglobin level of $20 \mathrm{~g} / \mathrm{L}\left[5^{\circ}\right]$.

\section{Hormonal Therapies}

In general, medical management of women with AUB includes any one of or combinations of estrogens, progestins, androgens, and GnRH agonists. However, the role of these agents in anticoagulated women with AUB has not been well determined and in fact, most, if not all of them, may be ineffective or contraindicated.

After an international survey among physicians, on handling hormonal contraceptive in anticoagulant-associated bleeding in premenopausal patients with venous thromboembolism (VTE) risk, they found the management in clinical practice is heterogeneous [10].

\section{Estrogens}

The use of estrogen in anticoagulated women requiring contraception remains controversial. According to the World Health Organization (WHO) guidelines, hormonal therapy with estrogen is category 4 (what is category 4?) and the "use of estrogen-containing contraceptives confers an unacceptable health risk" during established anticoagulant treatment of women with venous thromboembolism" [11]. In contrast, the Scientific and Standardization Committee of the International Society on Thrombosis and Haemostasis recommends that women can continue oral contraceptive and estrogen replacement hormonal therapy while on anticoagulant therapy [12]. This was supported by an additional study which reported that hormonal therapy was not associated with an increased risk of recurrent VTE in women receiving therapeutic anticoagulation [13].

\section{Progestins}

Treatment with progestins or progestin-loaded IUS has been tried and is considered relatively safe as a first line of treatment for patients with multiple risk factors that preclude definitive surgical treatment such as hysterectomy.

Oral and Injectable Progestins There was a difficulty in finding studies that evaluated oral or injectable progestin as a treatment for women on anticoagulation therapy with abnormal uterine bleeding. In a Cochrane review, women with abnormal uterine bleeding on oral cyclic progestin for 21 days had significantly less blood loss [14]. There were few studies on patients using anticoagulant therapy with oral or injectable progestin as contraceptive method. In terms of contraception, the WHO labeled oral and injectable progestin as category 2 (advantage outweigh risk) [11].

LNG-IUS Few studies have described the use of LNG-IUS in anticoagulated women presenting with AUB $\left[6^{\circ}, 15^{\circ}, 16^{\circ}\right]$. A randomized trial divided 40 women receiving anticoagulant therapy and complaining of menorrhagia to LNG-IUS vs. no intervention. Women treated with LNG-IUS had significant reduction in blood loss with increase in hemoglobin level after 3 and 6 months follow-up compared with non-intervention group $\left[15^{\circ}\right]$. A prospective study by Vilos et al. described 10 premenopausal women receiving warfarin therapy, after excluding endometrial pathology treated with LNG-IUS. At 5 years, the LNG-IUS remained effective in $70 \%$ of patients $\left[6^{\circ}\right]$. Although the use of the LNG-IUS had been reported to be an effective treatment in this group of women, in a survey conducted by Pisoni et al. on 23 patients on anticoagulant and used LNG-IUS to treat menorrhagia, 17 only returned the questionaire, $11.8 \%$ experienced worsening of bleeding, and $5.9 \%$ of them had no improvement of their AUB [16 ${ }^{\circ}$.

\section{GnRH Agonists}

GnRH agonists are one of the medical approaches for the management of dysfunctional uterine bleeding [17] through inducing hypo-estrogenism and endometrial atrophy, which subsequently improve hemoglobin level [18].

To our knowledge, there are only two published case reports describing the management of heavy bleeding associated with anticoagulation using GnRHa $\left[19^{\bullet *}, 20^{\circ}\right]$. The first case report described a patient with menorrhagia and fibroid uterus who presented with unstable angina and was treated with anticoagulant therapy. After heparin therapy, her bleeding became extremely heavy and she was started on goserelin depot $3.6 \mathrm{mg}$ subcutaneously monthly, and warfarin simultaneously. The patient underwent a stent procedure and 2 months later, the warfarin and goserelin depot were stopped and the patient underwent hysterectomy [19*0].

Another case report described a patient with positive heterozygous Factor V Leiden on long-term anticoagulation after an episode of DVT and pulmonary embolism. Due to episodes of persistent menometrorrhagia and decreased hemoglobin level, the patient was started on GnRHa (leuprolide acetate $3.75 \mathrm{mg}$ monthly) for 3 months. During treatment, the uterine bleeding decreased but did not stop completely so treatment was changed to a progestin intrauterine device placement and long-term oral progestin with improvement of the patient's abnormal uterine bleeding [20"*].

In the present case series, we report the use of GnRH agonist in 3 fully anticoagulated patients at high risk of recurrent VTE and/or PE. They were satisfied without the need to 
discontinue their anticoagulant, no new VTE and they were in complete amenorrhea.

In two young patients who are less than 50 years old, we decided to start them on add-back therapy as long-term use of GnRHa has adverse effect on bone density [21]; add-back therapy was suggested to avert bone loss and vasomotor symptoms without nullifying GnRHa therapeutic effect [22, $23]$. Both estrogen/progestin and progestin only were prescribed as add-back therapy with GnRH agonist [22, 23]. Norethindrone acetate is, unique only progestin, used as add-back therapy, has both estrogenic and androgenic properties, which effectively reduce GnRHa side effects [24, 25].

\section{Add-Back Therapy}

Add-back therapy is a low-dose hormone used to alleviate side effect of GnRHa while preserving its therapeutic efficacy. Current literature is mostly studying add-back therapy on patients with endometriosis or uterine fibroid, especially how to reduce the side effects of long-term use of GnRHa and hypoestrogenic state including progressive bone loss. In a prospective study, young women on GnRHa was followed for 1 year; patients who did not receive add-back treatment lost $6.3 \%$ of bone marrow density (BMD) [26]. In another randomized trial, add-back therapy with either regimen (norethindrone acetate $5 \mathrm{mg}$ /day alone or norethindrone acetate $5 \mathrm{mg} /$ day plus conjugated equine estrogens $0.625 \mathrm{mg} /$ day) successfully preserved bone health and improved quality of life [27].

Weighing risk of VTE and risk of bleeding should be kept in mind when treating women in reproductive age suffering from anticoagulation-associated heavy menstrual bleeding and each patient should have an individualize treatment.

\section{Conclusion}

In properly assessed and selected premenopausal women with AUB receiving anticoagulant therapy and at high risk for traditional therapies, long-term GnRHa was an effective treatment in 3 patients.

\section{Compliance with Ethical Standards}

Conflict of Interest The authors declare no conflicts of interest relevant to this manuscript.

Human and Animal Rights and Informed Consent All reported studies/ experiments with human or animal subjects performed by the authors have been previously published and complied with all applicable ethical standards (including the Helsinki declaration and its amendments, institutional/national research committee standards, and international/national/institutional guidelines.
Institutional Review and Patient Consent Clinical outcomes of women with abnormal uterine bleeding (AUB) treated by endometrial ablation and other medical therapies-HSREB 4913. All 3 women signed consent to publish their case.

Open Access This article is licensed under a Creative Commons Attribution 4.0 International License, which permits use, sharing, adaptation, distribution and reproduction in any medium or format, as long as you give appropriate credit to the original author(s) and the source, provide a link to the Creative Commons licence, and indicate if changes were made. The images or other third party material in this article are included in the article's Creative Commons licence, unless indicated otherwise in a credit line to the material. If material is not included in the article's Creative Commons licence and your intended use is not permitted by statutory regulation or exceeds the permitted use, you will need to obtain permission directly from the copyright holder. To view a copy of this licence, visit http://creativecommons.org/licenses/by/4.0/.

\section{References}

Papers of particular interest, published recently, have been highlighted as:

- Of importance

•- Of major importance

1. Fraser IS, Critchley HO, Broder M, Munro MG. The FIGO recommendations on terminologies and definitions for normal and abnormal uterine bleeding. Semin Reprod Med. 2011;29(5):383-90.

2. Singh S, Best C, Dunn S, Leyland N, Wolfman WL. No. 292abnormal uterine bleeding in pre-menopausal women. J Obstet Gynaecol Can. 2018;40:e391-415. https://doi.org/10.1016/j.jogc. 2018.03.007.

3. National Guideline Alliance (UK). Heavy menstrual bleeding (update). London: National Institute for Health and Care Excellence (UK); 2018.

4. Aletebi FA, Vilos GA, Eskandar MA. Thermal balloon endometrial ablation to treatment menorrhagia in high-risk surgical candidates. J Am Assoc Gynecol Laparosc 1999;6:435-9. Doi:https:// doi.org/10.1016/S1074-3804(99)80007-3. Study that has described the use of other treatment methods in anticoagulated women presenting with AUB.

5. Goldenberg M, Zolti M, Hart S, Bider D. Endometrial resectoscopic ablation in patients with menometrorrhagia as a side effect of anticoagulant therapy. Eur J Obstet Gynecol Reprod Biol. 1998;77:77-9. https://doi.org/10.1016/S0301-2115(97)00232-7 Study that has described the use of other treatment methods in anticoagulated women presenting with AUB.

6. Vilos GA, Tureanu V, Garcia M, Abu-Rafea B. The levonorgestrel intrauterine system is an effective treatment in women with abnormal uterine bleeding and anticoagulant therapy. J Minim Invasive Gynecol. 2009;16:480-4. https://doi.org/10.1016/j.jmig.2009.04. 018 Study that has described the use of other treatment methods in anticoagulated women presenting with AUB.

7. Van Eijkeren M, Christiaens G, Haspels A, Sixma J. Measured menstrual blood loss in women with a bleeding disorder or using oral anticoagulant therapy. Int J Gynecol Obstet. 1991;34:199-9. https://doi.org/10.1016/0020-7292(91)90284-C Study that shows the significance of AUB in patients using anticoagulants.

8. Själander A, Friberg B, Svensson P, Stigendal L, Lethagen S. Menorrhagia and minor bleeding symptoms in women on oral anticoagulation. J Thromb Thrombolysis. 2007;24:39-41. https:// 
doi.org/10.1007/s11239-006-0003-7 Study that shows the significance of AUB in patients using anticoagulants.

9. Huq FY, Tvarkova K, Arafa A, Kadir RA. Menstrual problems and contraception in women of reproductive age receiving oral anticoagulation. Contraception. 2011;84:128-32. https://doi.org/ $10.1016 /$ j.contraception.2010.12.011 Study that shows the significance of AUB in patients using anticoagulants.

10. Klok FA, Schreiber K, Stach K, Ageno W, Middeldorp S, Eichinger S, et al. Oral contraception and menstrual bleeding during treatment of venous thromboembolism: expert opinion versus current practice. Thromb Res. 2017;153:101-7. https://doi.org/10. 1016/j.thromres.2017.03.013.

11. World Health Organization, Reproductive Health and Research, World Health Organization. Medical eligibility criteria for contraceptive use. 2015. [Last accessed: 27/05/2019]. Avaliable from: https://www.who.int/reproductivehealth/publications/family planning/MEC-5/en/

12. Baglin T, Bauer K, Douketis J, Buller H, Srivastava A, Johnson G. Duration of anticoagulant therapy after a first episode of an unprovoked pulmonary embolus or deep vein thrombosis: guidance from the SSC of the ISTH: unprovoked VTE: duration of anticoagulation. J Thromb Haemost. 2012;10:698-702. https:// doi.org/10.1111/j.1538-7836.2012.04662.x.

13. Martinelli I, Lensing AWA, Middeldorp S, Levi M, BeyerWestendorf J, van Bellen B, et al. Recurrent venous thromboembolism and abnormal uterine bleeding with anticoagulant and hormone therapy use. Blood. 2016;127:1417-25. https://doi.org/10. 1182/blood-2015-08-665927.

14. Lethaby A, Irvine GA, Cameron IT. Cyclical progestogens for heavy menstrual bleeding. Cochrane Database Syst Rev. 2008. https://doi.org/10.1002/14651858.CD001016.pub2.

15•. . Kilic S, Yuksel B, Doganay M, Bardakci H, Akinsu F, Uzunlar $\mathrm{O}$, et al. The effect of levonorgestrel-releasing intrauterine device on menorrhagia in women taking anticoagulant medication after cardiac valve replacement. Contraception. 2009;80:152-7. https:// doi.org/10.1016/j.contraception.2009.02.007 Study that has described the use of other treatment methods in anticoagulated women presenting with AUB.

16. Pisoni CN, Cuadrado MJ, Khamashta MA, Hunt BJ. Treatment of menorrhagia associated with oral anticoagulation: efficacy and safety of the levonorgestrel releasing intrauterine device (Mirena coil). Lupus. 2006;15:877-80. https://doi.org/10.1177/ 0961203306071706 Study that has described the use of other treatment methods in anticoagulated women presenting with AUB.

17. Colacurci N, De Placido G, Mollo A, Perino A, Cittadini E. Shortterm use of Goserelin depot in the treatment of dysfunctional uterine bleeding. Clin Exp Obstet Gynecol. 1995;22:212-9.

18. Cetin NN, Karabacak O, Korucuoglu U, Karabacak N. Gonadotropin-releasing hormone analog combined with a low- dose oral contraceptive to treat heavy menstrual bleeding. Int $\mathrm{J}$ Gynecol Obstet. 2009;104:236-9. https://doi.org/10.1016/j.ijgo. 2008.10.032.

19.• Khurana C, Taylor P, de Belder MA. Corona stenting in a patient menorrhagia: use of a gonadotrophin releasing hormone agonist to facilitate anticoagulation. Int J Cardiol. 1998;63:89-91. https:// doi.org/10.1016/S0167-5273(97)00272-6. Case report describing the heavy bleeding associated with antigoagulation using GnRHa.

20.• Giustozzi M, Vedovati MC, Agnelli G. Management of heavy menstrual bleeding during direct oral anticoagulant therapy for recurrent venous thromboembolism: a case report. Blood Coagulation \& Fibrinolysis. 2018;29:391-4 Case report describing the heavy bleeding associated with antigoagulation using GnRHa.

21. Nencioni T, Penotti M, Barbieri-Carones M, Ortolani S, Trevisan C, Polvani F. Gonadotropin releasing hormone agonist therapy and its effect on bone mass. Gynecol Endocrinol. 1991;5:49-56. https:// doi.org/10.3109/09513599109049941.

22. Thomas EJ, Okuda KJ, Thomas NM. The combination of a depot gonadotrophin releasing hormone agonist and cyclical hormone replacement therapy for dysfunctional uterine bleeding. Br J Obstet Gynaecol. 1991;98:1155-9. https://doi.org/10.1111/j.14710528.1991.tb15369.x.

23. Thomas EJ. Add-back therapy for long-term use in dysfunctional uterine bleeding and uterine fibroids. Br J Obstet Gynaecol. 1996;103(Suppl 14):18-21.

24. Adashi EY. Long-term gonadotropin-releasing hormone agonist therapy:the evolving issue of steroidal "add-back" paradigms. Keio J Med. 1995;44:124-32. https://doi.org/10.2302/kjm.44.124.

25. Chwalisz K, Surrey E, Stanczyk FZ. The hormonal profile of norethindrone acetate: rationale for add-back therapy with gonadotropin-releasing hormone agonists in women with endometriosis. Reprod Sci. 2012;19:563-71. https://doi.org/10.1177/ 1933719112438061.

26. Hornstein MD, Surrey ES, Weisberg GW, Casino LA. Lupron addBack study group. Leuprolide acetate depot and hormonal add-back in endometriosis: a 12-month study Obstet Gynecol 1998;91(1):1624. https://doi.org/10.1016/S0029-7844(97)00600-5.

27. DiVasta AD, Feldman HA, Sadler Gallagher J, Stokes NA, Laufer MR, Hornstein MD, et al. Hormonal add-back therapy for females treated with gonadotropin-releasing hormone agonist for endometriosis: a randomized controlled trial. Obstet Gynecol. 2015;126: 617-27. https://doi.org/10.1097/AOG.0000000000000964.

Publisher's Note Springer Nature remains neutral with regard to jurisdictional claims in published maps and institutional affiliations. 